\title{
Innovation, High Technology Sectors, Higher Education and Human Capital: Education System Reform in Georgia
}

\author{
Megi Kurdadze
}

Received: 17 November 2009/Accepted: 9 February 2010/Published online: 24 June 2010

(C) The Author(s) 2010. This article is published with open access at Springerlink.com

\begin{abstract}
Reforms and changes in order to meet European standards were top priority. First steps towards legislative reform were taken in June 2001, when the parliament of Georgia initiated a project aiming to determine the main directions of education system development in Georgia. Education system reform in Georgia started in 2004 and lasted until 2007 with changes in the spheres of financing, management, teaching methods.
\end{abstract}

Keywords Higher education · Human capital · Innovation

JEL Classification $\mathrm{I} 20 \cdot \mathrm{I} 23 \cdot \mathrm{I} 28$

Mankind has been discussing the role of education for centuries, and perceives its necessity to be the recognized truth. However, the meaning of education is the subject of permanent research and fresh comprehension is the process of development of human beings, societies and countries. Nowadays variable environment has become a new challenge for the whole system of education.

World cataclysms and unplanned changes in development of countries, whose changes hardly can be predicted, have elaborated a "new" role for education. A person should receive not only accumulated sound knowledge and experience but, first of all, master the skills that can easily get a person accustomed to different changes and unexpectedness the meaning of education not concerning establishment of a concrete person, but apprises the role of education in development of the whole society.

Mankind, ruined in the aftermath of World War II, directed its view to education as the main resource that would lead countries out of post-war poverty and put them

M. Kurdadze (ه)

Georgian Institute of Public Affairs, Tbilisi, Georgia

e-mail: m_kurdadze@yahoo.com 
onto a new stage of development. And it was after the war when there developed the so-called theory of "Human Capital", which was especially strengthened in 1950s and 1960s, and placed education in the center of the world's optimistic view of development. Education was not reviewed as one of the competitive consumer goods that could be bought personally (for personal application) or collectively (for increasing society's welfare through taxes). It was reviewed as the most advantageous investing opportunity. This meant that growing expenses for education and its access would increase social profit and improve the quality of society's welfare.

This was the epoch of optimistic view and disposition towards world development and establishment of equality. It was believed that education would quickly fill the gap existing between the countries in different stages of development: the industrial countries ruined in the aftermath of the war would quickly recover, and non-industrial and poor countries would quickly and follow their way of development easily enough.

Directed by this belief, the countries began investing more and more capital in development of the system of education. But one of the most important components was measures promoting access to education.

It has become clear that direction of most state means to education hoping that educated people shall become guarantors of development of the country and critical resource is not enough. The reforms need a much more complex approach.

- Georgia/Main Facts: Population: 4.4 million (2009).

- General education: 630,000 pupils/70,000 teachers/2,500 schools.

- Higher education: 150,000 students.

The Ministry of Education and Science of Georgia made complex changes in its education system, and reforms met European standards, which became a top priority for Georgia. Attaining this goal in a relatively short period of time, through the given resources and in line with progressive development is an essential precondition for sustainable development, social cohesion, economic growth and international co-operation. Despite the multiple attempts of the Georgian government to restructure the old Soviet system since 1991, progress was not tangible. Quite the opposite: the mix of old and new models engendered considerable repercussions, such as corruption, favoritism, nepotism and, the most alarming: dilution of quality. The first actual steps towards legislative reform were taken in June 2001, when the parliament of Georgia initiated a project aiming to determine the main directions of education system development in Georgia.

Education system reform in Georgia began in 2004 and lasted until 2007. It began with the changes in the spheres of financing, management, teaching methods. It prepared different conceptions, decrees, changed the legislative base, created introductions of new models of financing and management, renewed the teaching methods and contents, made decentralization of management, increased the quality control of education, the government increased educational and research institutions' autonomy. Now it pays much more attention to teacher training and also training of the administration of the education system institutions. During the reform we 
renewed resources and made new information-communication infrastructures, adopted social trainings and supplementary materials for teachers. The most important is to foresee international experience and focus on European standards.

Reform began with the changes in the spheres of financing, management, teaching methods. The most important is to foresee international experience, prepare different conceptions, change the legislative base, introduce new models of financing and management; renew the teaching methods and contents, create decentralization of management. The Georgia Ministry of Education pays attention to control of the quality of education. We try to increase educational and research institutions' autonomy. The most important issue is teacher trainings and also training of the administration. With government support and renewed resources at schools and in the universities, we made new information-communication infrastructures. The Ministry of Education of Georgia maintains special training and supplementary materials for teachers. If we evaluate the period before reform and after reform, we can see the differences in how motivated pupils and teachers are, as well as the difference of the infrastructures. In Georgia the main principles of teaching methods have also changed. For example before it was teacher-oriented and now it is studentoriented, from discipline-based it has now become problem-based.

Most important is

- A professional, motivated teacher in a class;

- Elaborated curriculum getting a child prepared for further stages, the workplace or honorable integration into a society;

- Modern text-books, technologies and methodological support literature;

- Effective administration and management of the school/institutes thus creating encouraging culture for learning and friendly environment; and

- Safe learning environment.

Nowadays, higher education is one of the determining factors of the intellectual and productive forces of society reproduction, of the development of spiritual culture of the Ukrainian people, the guarantor of future success in consolidation and strengthening of the authority of Georgia as a sovereign, independent, democratic, social and law-based state. This is one of the priorities. The process of integration of Europe, its move to the East, is followed up by the creation of general education and scientific areas, development of unified criteria and standards in the field of education and science, where the quality of higher education is the basis for the formation of this area. The problem of quality of education has never been of such great ideological, social, economic and technical importance as it is today. Putting forward the problem of quality has objective reasons: firstly, the quality of human resources determines the level of development of the country and its global economic competitiveness; secondly, the quality of education gets more and more important in providing competitiveness of higher school graduates in the labour market.

The basic principles that cause development of the higher education system of Georgia in modern conditions are: creation of innovation environment on the basis of educational and scientific support. This is the modern way of development of society that can be provided only if a generation of people is formed who think and act in an innovative way. This gives rise to a greater attention to the general 
development of a person, his communicative abilities, gaining knowledge, and independence in taking decisions, critical approach and culture of thinking, formation of informational and social skills. Such approaches are determined by the main pedagogical idea of contemporaneity: life-long education.

According to the newly adopted law on higher education, establishing a sound and responsive higher education system that meets European standards has become a top priority. Attaining this goal in a relatively short period of time, through the given resources and in line with the progressive development is an essential precondition for sustainable development, social cohesion, economic growth and international co-operation. Despite the multiple attempts of the Georgian government to restructure the old Soviet system, progress was not tangible. Quite the opposite, the mix of old and new models engendered considerable repercussions, such as corruption, favoritism, nepotism and, the most alarming: dilution of quality. The first actual steps towards legislative reform were taken in June 2001, when the parliament of Georgia initiated a project aiming to determine the main directions of higher education development in Georgia. A task force of Georgian and European experts was immediately set up. Consequently, eleven background papers were drafted on the higher education system of Georgia. The papers covered such topics as accreditation, attestation, licensing, quality assurance, student admission, academic staff, financing, evaluation, governance, private higher education institutions (HEI), and the labour market. Students were involved in drafting the texts alongside more than 20 local and international universities and institutions. The Parliament of Georgia adopted a decree on the "Main Directions of Higher Education Development in Georgia". The decree contains the aims, objectives and principles of the Georgian higher education system that are also defined in the recently adopted Georgian Law on Higher Education (December, 21, 2004).

According to the Georgian Law on Higher Education, the quality assurance system includes evaluation of HEIs and programmes through self-evaluation, external review, and participation of students and publication of results. Through the evaluation of HEIs compliance of the material and human resources of a HEI with the minimum criteria stated by the Ministry of Education and Science of Georgia is assessed. All the state and private HEIs have to undergo the procedure, otherwise it might become a reason for not issuing license or shutting down an institution. Evaluation of programmes includes assessment of credibility of aims, objectives and content of a programme; its methodology, organization and assessment criteria; achievements of students and individual work with them, resource provision for teaching; potential mechanisms for raising the quality of teaching etc.

\section{Achievement of European Recognition}

- Georgia has been a member of European Council;

- Increasing number of overseas students;

- Increased mobility of students and academic staff;

- Enhance quality of teaching and learning; and

- Joining Bologna; 
Integration of Georgia in the Bologna Process is very important for the future development of human thinking and society. Enlargement prospects together with deepening relations with other European countries provide even wider dimensions to that reality. Meanwhile, we are witnessing a growing awareness in large parts of the political and academic world and in public opinion of the need to establish a more complete and far-reaching Europe, in particular building upon and strengthening its intellectual, cultural, social and scientific and technological dimensions. A Europe of Knowledge is now widely recognized as an irreplaceable factor for social and human growth and as an indispensable component to consolidate and the European citizenship, capable of giving its citizens the necessary competences to face the challenges of the new millennium, together with an awareness of shared values and belonging to a common social and cultural space.

The importance of education and educational co-operation in the development and strengthening of stable, peaceful and democratic societies is universally acknowledged as paramount.

According to the law on higher education, one of the main priorities of the state policy is to assure academic freedom of study and research, provide and develop the necessary conditions for research, and bring the Georgian research system into line with European standards. Moreover, the law on higher education underlines the primary significance of the research within HEIs. The Academic Board of a HEI is entitled to approve the research programmes and determines the rules of evaluation of a research work. The law stipulates that funds for conducting a master and doctoral degree research will be taken from the state research fund on a competitive basis and in view of priorities determined by the Ministry of Education and Science of Georgia.

Until now the basic factors facilitating mobility of teachers and staff have been the grant schemes supported by a number of international organizations. Currently the law stipulates that international cooperation and mobility of teachers is the basic precondition for ensuring high quality at HEIs. The ongoing reform envisages attaching great importance to constant professional development of teachers and staff; therefore, their participation in mobility schemes shall be supported at a state level. In Georgia everyone has a right to get free education in any state HEI regardless of gender, race, nationality, social and economic status, type and nature of activities, world views, belonging to parties, attitude towards religion, religious conscience, state of health, place of residence and other circumstances.

The experts gave a highly positive evaluation of the ongoing reforms in Georgia and shared their views and suggested recommendations on further actions to be taken towards joining the Bologna Process. The transitional provisions of the law on higher education stipulate that all HEI-s shall ensure complete adoption of the threecycle degree system before the 2007-2008 academic years. The ECTS shall be universally introduced before the 2009-2010 academic year. In 2006-2007 the Ministry of Education and Science of Georgia shall examine the licensing conditions of those private HEIs that do not take part in institutional accreditation before the 2006-2007 academic year. In 2006-2007 the duration of master programmes at all HEIs should not be less than 2 years. The overall programme accreditation shall commence in the 2007-2008 academic year. 


\section{Conclusion}

Transition to the new model of education system requires much effort and mobilization of human, material and financial resources. The government of Georgia is committed to assisting the process by all possible means. Therefore, it is crucial to provide conditions for high quality education, life-long learning, innovative research and mobility. At present, the crucial challenge ahead for Georgia is to implement the Georgian Law on Education effectively and efficiently. As noticed above, the law envisages approximation of the Georgian education system with the European standards. In this regard, wider social participation especially student involvement as well as international cooperation plays a vital role. The Ministry of Education and Science of Georgia together with the HEIs and 12 civil society is committed to collaborating in making Georgia one of the most dynamic and competitive places in Europe where it is desirable to teach, research and study.

The education system fully reflects the overall cultural and socio-economic situation in the country. The institutional improvement of systems in general will impact the educational system. Moreover, unless education system development is accompanied by socio-economic development, the road to the civil society will be full of obstacles.

The analysis of the education system state in transitional economies shows that the process of harmonization of the higher education system to the European educational system meets rather essential obstacles. Basically it is reflected in the absence of corresponding legislative-standard bases, or their undeveloped state does not meet the requirements in the context of Bologna process. In other words, institutional aspects of educational systems integration in the all-European educational space are absent.

On the other hand, inveterate stereotypes on the system of educational process organization as a whole are creating obstacles. The presence of rigid standards and non-flexible technologies of training makes the realization of one of the main postulates of the Bologna process-freedom in choosing individual trajectory of training-impossible.

Another problem is the conservative spirit of the academic community of the academic system, caused by unwillingness of evolution of outlook on new realities.

We would like to point out the fact that the absence of freedom in making administrative decisions, particularly, the insufficient freedom in the management of financial resources on the one hand and absence of necessary and sufficient financing from the government on the other, makes the implementation of reforms impossible, because as the known postulate says "reform means money", so this brings us to the paradox. And, despite the proclaimed cooperation in the context of unification of development, directions on a global scale and in the sphere of integration of educational spaces in particular, the cooperation with corresponding structures is insufficient.

One of the core problems in the educational system development is the absence of interest within the private business and the government on the held reforms, as well as the lack of public consciousness. It is our strong belief that Public-Private 
Partnerships could be a good model to supply the provision of infrastructure, amenities, by the means of tax privileges, preferential rent and other mechanisms for the business to be interested in the public projects. This will improve the educational quality in compliance with the "leave no person behind" policy.

To conclude, the reform of the system of education is just a component of endeavours directed to development of the country. It should be viewed in a wider context and related to economic, cultural, social reforms focused on increasing of economic activity implementation of the labour culture, enhancement of social knowledge, efficient application of the human resources.

Open Access This article is distributed under the terms of the Creative Commons Attribution Noncommercial License which permits any noncommercial use, distribution, and reproduction in any medium, provided the original author(s) and source are credited. 